Photogallery

\title{
In situ observation of Denise's pygmy seahorse Hippocampus denise associated with a gorgonian coral Annella reticulata at Osprey Reef, Australia
}

\author{
Jun NISHIKAWA ${ }^{1, *}$, Richard FITZPATRICK ${ }^{2}$, James D. REIMER ${ }^{3}$, Robin J. BEAMAN², \\ Hiroyuki YAMAMOTO ${ }^{4}$, and Dhugal J. LINDSAY
}

\author{
${ }^{1}$ Atmosphere and Ocean Research Institute, University of Tokyo, 5-1-5 Kashiwanoha, Kashiwa, Chiba 277-8564, Japan \\ 2 James Cook University, McGregor Road, Smithfield, Cairns, Qeensland 4870, Australia \\ ${ }^{3}$ Transdisciplinary Research Organization for Subtropics and Island Studies, University of the Ryukyus, 1 Senbaru, \\ Nishihara, Okinawa 903-0213, Japan \\ ${ }^{4}$ Japan Agency for Marine-Earth Science and Technology, 2-15, Natsushima, Yokosuka, Kanagawa 237-0061, Japan \\ * Corresponding author: J. Nishikawa \\ E-mail: jn@aori.u-tokyo.ac.jp \\ Communicated by Saki Harii (Ecology Editor)
}

Keywords Hippocampus denise, Osprey Reef, pygmy seahorse, Annella reticulata, ROV

Hippocampus denise Lourie and Randall, 2003, one of the world's smallest seahorses, was described from Indonesia and appears to be relatively widespread in the West Pacific (Lourie and Randall 2003). The widespread occurrence of this species has been recorded in books, dive magazines and on the internet (e.g. Kuiter 2000), and recently the occurrence of this species was reported from Holmes Reef (Coral Sea) based on samples collected, together with gorgonians Villogorgia sp. from a depth of 100 m (Foster et al. 2012). Biological and ecological data on this species are, however, very limited as well as in situ observations of this species at such great depths.

Underwater observations using a high-definition video camera on the untethered remotely operated vehicle, PICASSO-1 (Fig. 1a), enabled us to confirm the occurrence of this species at Osprey Reef, a Coral Sea atoll in Australian waters, the first in situ record from this isolated oceanic reef, and even to measure breathing rates $(2-5 \mathrm{~Hz})$ and swimming distances (2.3-4.5 x body length) (see supplementary video footage). While no specimens of the observed seahorses were sampled, it is clear that the species we observed has a very low number of tubercles on its ventral region, and has an orange body color (see Fig. 1c). Based on these characters, the fishes were identified as $H$. denise. Three individuals ( 1 male and 2 females) were found on the branches of a gorgonian, Annella reticulata (Ellis and Solander, 1786), of size $1.72 \times 1.53 \mathrm{~m}$ (Fig. 1b) on the steep reef wall near a prominent point of Osprey Reef $\left[13.888368^{\circ} \mathrm{S}, 146.555328^{\circ} \mathrm{E}\right.$ ] at a depth of $102 \mathrm{~m}$ (water temperature $23.7^{\circ} \mathrm{C}$ ), the deepest record of this species to date in the literature. This depth is similar to that reported in Foster et al. (2012) at Holmes Reef, suggesting that the occurrence of $H$. denise at such extreme depths may not be uncommon. Hippocampus denise was observed to only occur on A. reticulata among several species of gorgonians observed. The standard length (SL, as in Lourie and Randall 2003) measured from framegrabs of the fish was $21.5 \mathrm{~mm}$ for a "pregnant” male (Fig. 1c).

The approach of non-destructive sampling through the use of high-definition video allows both identification and behavioral observations to be made in situ in the mesophotic environment over prolonged periods. Future genetic examinations of this species will provide a clearer understanding of how such a host-specific and diminutive seahorse is able to settle and maintain their populations at 
isolated oceanic reefs.

\section{Acknowledgments}

The authors thank Dr. Pim Bongaerts for the review of this manuscript. We also appreciate all participants on the Coral Emperor cruise of 1-17 May 2011. This study was supported by the funds provided by JAMSTEC, AIMS, James Cook University, University of the Ryukyus, the production of the 'Great Barrier Reef' series by Digital Dimensions, BBC, Discovery Channel and Channel 9, and the fund for Interdisciplinary Collaborative Research by the Atmosphere and Ocean Research Institute, University of Tokyo.

\section{References}

Foster R, Bridge TCL, Bongaerts P (2012) The first record of Hippocamus denise (Syngnathidae) from Australia. Aqua, Int J Ichthyol 18: 55-57

Kuiter RH (2000) Seahorse, pipefishes and their relatives. TMC Publishing, Chorleywood, UK

Lourie SA, Randall JE (2003) A new pygmy seahorse, Hippocampus denise (Teleostei : Syngnathidae), from the Indo-Pacific. Zool Stud 42: 284-291

Online Supplementary Material. A movie is available at http://www.jstage.jst. go.jp/browse/galaxea.

Received: 1 June 2011/Accepted: 5 September 2011

(C) Japanese Coral Reef Society
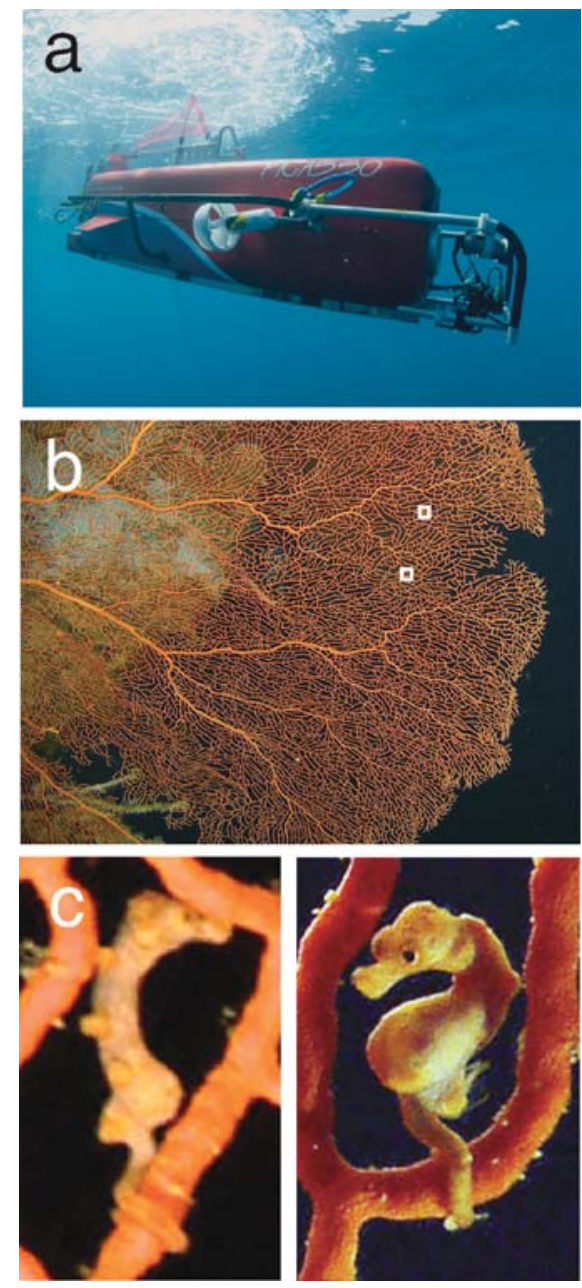

Fig. 1 a The remotely operated vehicle, PICASSO-1 used in this study. b A host gorgonian, Annella reticulata. White squares indicate the position of the seahorse framegrabs. See supplementary video footage. c Hippocamus denise video-recorded in situ on the host gorgonian. Left: female. Right: male 